\title{
O papel da bibliografia na construção do conhecimento em Ciência da Informação: o caso da Escola de Ciência da Informação da UFMG
}

\section{Cristina Dotta Ortega}

\begin{abstract}
Pós-doutorado pela Universidade Federal Fluminense, Doutora em Ciência da Informação pela Universidade de São Paulo. Professora adjunta da Escola de Ciência da Informação da Universidade Federal de Minas Gerais.
\end{abstract}

Maria da Conceição Carvalho

Doutora em Estudos Literários pela Universidade Federal de Minas Gerais. Professora associada da Escola de Ciência da Informação da Universidade Federal de Minas Gerais.

http://dx.doi.org/10.1590/1981-5344/3232

O objetivo deste estudo é caracterizar o papel da Bibliografia enquanto disciplina do campo da Ciência da Informação tomando como fonte de referência o modo como tal disciplina foi apropriada pela Escola de Ciência da Informação/UFMG, desde os primeiros anos do Curso de Biblioteconomia, em 1950, até os dias atuais. Primeiramente será apresentada uma sistematização conceitual sobre o tema com a finalidade de colocar em discussão as imprecisões ligadas à noção de "bibliográfico". Em seguida é apresentado um relato de experiência acadêmica procurando mostrar o processo evolutivo da disciplina Bibliografia na história da Escola de Ciência da Informação/UFMG: dos anos iniciais do curso à estruturação em departamentos; da transposição didática de conteúdos da matéria do curso de graduação em Biblioteconomia ao curso de pós-graduação em Ciência da Informação; e da significativa produção científica de alunos e professores pesquisadores à desvalorização da disciplina como campo teórico na esteira de uma tendência mundial. Como conclusão, enfatiza-se a importância da Bibliografia como disciplina estrita, como também de estudos sobre o sistema bibliográfico na 
perspectiva de dispositivo elaborado para funcionar como proposta de percurso cognitivo sobre documentos, com o fim de contribuir para fomentar o uso qualificado da informação, promovendo a inserção cultural do sujeito no mundo informacional.

Palavras-chave: Bibliografia. Ensino e pesquisa em Bibliografia. Escola de Ciência da Informação da UFMG.

\section{The role of Bibliography in the development of knowledge in Information Science: the case of the School of Information Science at UFMG}

This paper aims at characterizing the role of Bibliography as a discipline in Information Science having as reference how this subject was appropriated by the School of Information Science/UFMG, since the beginning of the Librarianship course, in the beginning of 1950 up to the present day. Firstly, this paper brings a conceptual systematization on this topic with the purpose of putting into question the inaccuracies linked to the notion of "bibliographic". Then it presents a report of academic experience in order to show the evolutionary process of the course Bibliography in the history of the School of Information Science/UFMG: from the initial years to the organization in departments; from the didactic transposition of contents of Bibliography in the undergraduate course in Librarianship to the postgraduate course in Information Science; from the significant scientific production of students and research professors to the devaluation of that course as a theoretical field, in the wake of a worldwide trend. As a conclusion, the importance of Bibliography as a strict course is emphasized, as well as studies about the bibliographic system as a device designed to function as a cognitive path on documents so as to contribute to foster the qualified use of information, promoting the cultural insertion of the subject in the informational world. 
Keywords: Bibliography. Bibliography - teaching and research. School of Information Science - UFMG.

Recebido em 31.05.2017. Aceito em 30.06.2017

\section{Introdução}

A Bibliografia é aqui abordada como vertente ou disciplina constituinte do campo da Ciência da Informação, entendida como parte do conjunto de atividades sobre documentos em abordagem bibliográfica, cujo objetivo é fomentar e satisfazer necessidades de informação de um público. Para tratar da abordagem bibliográfica em sua completude, é necessário ter em conta mais de uma disciplina, quais sejam, a Bibliografia, a Biblioteconmia e a Documentação. Nessa perspectiva, o trabalho bibliográfico é emblemático do campo de estudo e da prática bibliotecária.

A especifidade da abordagem bibliográfica coloca-se em relação às abordagens arquivística e museológica, uma vez que todas refletem a produção e oferta de mensagens sobre documentos a um público destinatário. Dentre os estudos tratados em Ciência da Informação, os de abordagem bibliográfica foram os mais presentes na literatura técnicocientífica mas, paradoxalmente, são os mais difíceis de definir, segundo nossa observação. Desse modo, uma aproximação à conceituação do trabalho bibliográfico é realizada a seguir a partir de alguns dos elementos que o contemplam.

O trabalho bibliográfico orienta-se a diversos fins como: a construção de conhecimento, necessário a atividades educacionais, científicas e profissionais; a fruição ou experiência estética; e os utilitários, relativos ao acesso a serviços ou atividades de entretenimento, educação, cultura, saúde e direitos civis.

Quanto aos ambientes em que o trabalho bibliográfico ocorre, temos, de modo emblemático, as bibliotecas, mas também, centros de documentação, centros de memória, sistemas ou redes de informação, entre outras denominações similares adotadas. Por sua vez, independente do ambiente e de sua denominação, podemos falar nos seguintes sistemas ou produtos resultantes desse trabalho: bibliografias nacionais; bases de dados especializadas; bases de dados cadastrais (eventos, especialistas, outros); catálogos comerciais (de livrarias, por ex.); sistemas de informação ao cidadão; bases de dados bibliométricas; sistemas de produção de revistas eletrônicas; e portais de informação da Internet.

O trabalho bibliográfico é realizado por meio de atividades, como: seleção, representação, ordenação (arranjo), preservação, serviços, exposições. Assim, considerando as práticas seculares de produção de repertórios bibliográficos e aquelas realizadas em bibliotecas, podemos 
dizer que conteúdos selecionados, descritos e ordenados segundo interesses previamente identificados se mostraram socialmente relevantes, conduzindo a composições disciplinares próprias.

O objetivo deste estudo é o de explorar o papel da Bibliografia em Ciência da Informação, por meio da caracterização da disciplina em uma perspectiva histórica e conceitual e da análise de sua apropriação pela Escola de Ciência da Informação da UFMG, desde sua fundação em 1950 até os dias atuais.

Do ponto de vista da estrutura formal, o trabalho é composto por Introdução (tópico 1), seguida de sistematização sobre o tema (tópico 2) e de relato de experiência acadêmica (tópico 3 ).

A sistematização sobre o tema foi realizada em duas partes, com o objetivo de explicitar sua especificidade, haja vista que a derivação 'bibliográfico' é extensamente adotada mas, segundo observamos, encontra-se fracamente definida. Na primeira parte, tratamos da Bibliografia, da Biblioteconomia e da Documentação, por considerarmos que as três disciplinas desenvolveram ênfases próprias sobre o mesmo objeto, as quais são necessárias para sua compreensão efetiva. A segunda parte trata das origens da Bibliografia e dos elementos que a caracterizaram, incluindo sua relação com os elementos das outras duas disciplinas citadas, de modo que possamos observá-la com maior propriedade nos dias de hoje.

Como relato de experiência acadêmica, abordamos o caso da Escola de Ciência da Informação da UFMG, discorrendo sobre o lugar ocupado pela Bibliografia na organização departamental, segundo a concepção epistemológica adotada para os agrupamentos disciplinares propostos no decorrer do tempo. Em seguida, abordamos a transposição didática dos conteúdos de Bibliografia para o curso de graduação em Biblioteconomia, assim como, a resposta da sociedade, em um certo momento, frente a trabalhos desenvolvidos por alunos no campo específico das biobibliografias. Por fim, exploramos a produção científica sobre Bibliografia realizada nesta Escola pelos seus professores, que podemos considerar como única no contexto brasileiro, além da concepção e produção da pós-graduação. A opção pelo estudo de caso se deve ao entendimento de que observar a experiência de uma instituição de ensino superior contribui para entender a manifestação concreta de um determinado conhecimento em atividades de pesquisa e de ensino, e posteriormente, na prática profissional. Considerando o longo percurso das atividades desta Escola e a abrangência de sua atuação em diversos níveis de ensino e na pesquisa, podemos afirmar que esta instituição desempenha papel significativo no país quanto ao tema da Bibliografia. A realização de estudos sobre este tema, tal qual foi desenvolvido na Escola, é relevante, também, no que tange à construção da memória institucional, 
pois permite identificar seus caminhos e as possíveis implicações deles para os desafios atuais.

\section{Sobre Bibliografia}

\subsection{Bibliografia, Biblioteconomia e Documentação}

O produto a que depois se denominou bibliografia recebeu inicialmente outros nomes, entre eles, o nome metafórico biblioteca, que predominou durante quase três séculos, cujo fato indica, para Balsamo (1998), a relação estreita existente entre o momento de coleta de documentos e o de organização da informação. Para este autor, o termo bibliografia não foi adotado até o século XVII, e seu uso formal para indicar repertórios ou listas de livros só foi definitivamente generalizado durante o século XIX. Balsamo afirma que o surgimento das bibliografias está diretamente relacionado à formação de bibliotecas de instituições abertas ao público nas quais foram aplicadas, de tal modo que o registro produzido em repertórios e em catálogos constituiu a base para a construção doutrinária das duas disciplinas (BALSAMO, 1998, p. 13, 15).

Também Meneses Tello (2007, p. 117) afirma que é certo que a bibliografia, como ferramenta da pesquisa bibliográfica, e a biblioteca, como sistema de acervos e serviços bibliotecários, são fenômenos intelectuais a disposição dos leitores e usuários que buscam satisfazer necessidades sociais de informação.

Assim, a Biblioteconomia constituiu-se como disciplina de modo mais efetivo do século XIX para o XX, tendo como principal referência 0 trabalho em bibliotecas com seus acervos e serviços. Relativamente contemporânea a ela, a Bibliografia recebeu maiores contornos disciplinares a partir do desenvolvimento das técnicas de produção de repertórios bibliográficos, associadas aos estudos sobre o livro e os impressos em geral.

Essa atividade de produção de repertórios bibliográficos foi recolocada no decorrer do século $X X$ na perspectiva da Documentação, a partir de métodos e instrumentos voltados ao tratamento de conteúdos temáticos e das partes dos documentos e na perspectiva de uma maior diversidade documental. A Bibliografia inicialmente, e também a Documentação posteriormente, conduziram, em especial, ao trabalho com a informação técnico-científica pelos diversos tipos de sistemas e serviços de informação especializada. É preciso registrar (MENESES TELLO, 2007, p. 124) que a Bibliografia manteve sua autonomia frente à Documentação, como podemos observar em alguns programas de ensino, na atuação das bibliotecas nacionais e na continuidade das publicações e outras ações pelas sociedades bibliográficas criadas no final do século XIX 
e início do XX na Inglaterra, Estados Unidos e Canadá. Por sua vez, no mesmo período, a Biblioteconomia - na perspectiva estrita das bibliotecas, como falamos - também desenvolveu viés voltado à informação técnicocientífica, constituindo a chamada Biblioteconomia Especializada.

Atualmente temos na denominação Biblioteconomia e Ciência da Informação (BCI) - usualmente, Library and Information Science (LIS) -, de orientação anglo-americana, a vertente predominante do campo. Sob o ponto de vista desta vertente, a contribuição da Documentação não é ressaltada, até porque não é suficientemente conhecida nesse espaço cultural. Ela é, no entanto, vertente significativa no pensamento europeu continental, como é o caso da França e da Espanha, entre outros países. Nas escolas brasileiras, a Documentação tem representatividade em algumas delas, enquanto a Bibliografia foi muito presente, até a década de 1970 aproximadamente, nos primeiros cursos de graduação em Biblioteconomia e, como decorrência, nas práticas profissionais.

Bibliografia, Biblioteconomia e Documentação podem ser entendidas como disciplinas constituintes do campo da Ciência da Informação que se ocupam da abordagem bibliográfica. A denominação Ciência da Informação é a mais recente e a mais ambígua dentre as citadas. No Brasil, ela é adotada para indicar as atividades de pesquisa e de formação para a pesquisa no campo. Muitas vezes, Ciência da Informação é termo utilizado para congregar as atividades de pesquisa relativas às questões bibliográficas que discutimos aqui, outras vezes incorpora também questões de ordem arquivística e museológica e, outras vezes ainda, várias possibilidades de estudos informacionais, ou assim chamados, são alocados sob este nome.

Visando contemplar objeto teórico construído no tempo associado a demandas sociais concretas por informação, o reconhecimento da anterioridade da Bibliografia, simultaneamente ao seu estatuto contemporâneo, é apresentado no próximo tópico.

\subsection{Bibliografia: origens e atualidade}

Considerando a Bibliografia como um dos campos de atividade do complexo sistema de comunicação social, Balsamo (1998, p. 11, 16) entende o produto do trabalho bibliográfico - a bibliografia - como um mecanismo particular da memória secundária da informação. Para ele, no que tange à Ciência da Informação, a continuidade da tradição bibliográfica é clara, sobretudo nos aspectos estruturais da formação e do uso da memória coletiva.

Anteriormente, no entanto, no Dictionnaire raisonné de Bibliologie, publicado em 1802, Gabriel Peignot, segundo Couzinet (2011), introduziu uma distinção: a Bibliografia e a Bibliologia. Enquanto a Bibliografia seria 
um dos ramos da Bibliologia, voltada aos aspectos técnicos e à elaboração de repertórios de livros, esta envolveria o estudo histórico e científico do livro e os conhecimentos filosóficos, históricos e literários relativos à bibliografia. Segundo Peignot, em concepção que nos parece bastante atual, a Bibliografia é o fio que deve guiar o amador no labirinto literário nomeado biblioteca; é ela que deve dirigir sua escolha e fixá-lo sobre as melhores obras, sobre as melhores edições (COUZINET, 2011, p. 178, citando RICHTER, 2007). Assim, cabe relevar o entendimento do autor, àquela época, sobre o sistema bibliográfico como dispositivo que deve funcionar como proposta de percurso cognitivo sobre documentos.

Já a Bibliometria, enquanto trabalho bibliográfico, desenvolveu-se sob o aporte estatístico com fins de obtenção de medidas sobre a produção do conhecimento registrado. Os primeiros trabalhos bibliométricos foram realizados como aplicação da medida da produção e circulação dos livros no século XVIII, mas a técnica e função bibliométrica foi efetivamente proposta por Otlet em seu Traité de Documentation, de 1934 (COUZINET, 2011, p. 182). Mais que isso, para Couzinet (2011), apoiando-se em publicações da década de 1990, o uso da técnica bibliométrica ocorre também na gestão dos acervos e serviços de bibliotecas. Demonstra-se aí a abrangência, a especificidade e a historicidade da prática bibliométrica, efetivamente continuada no tempo, a despeito da grande presença bastante recente de estudos bibliométricos na pesquisa acadêmica do campo em vários países.

Quanto aos tipos de documentos e suportes tratados pela Bibliografia, os livros e impressos em papel eram centrais, uma vez que se apresentavam como as principais formas documentais escritas no século XIX. No entanto, a descoberta dos repertórios de manuscritos da Antiguidade, e seu estudo por especialistas, levaram a que estes materiais fossem incluídos entre os interesses da Bibliografia, assim como, os textos eletrônicos, que são hoje foco de interesses diversos, não escapam aos olhares desta disciplina (COUZINET, 2011, p. 168). Independentemente do modo como os escritos são fixados, seja em rolos de papiros ou pergaminhos, seja por meio de dígitos binários, a questão primordial é a do interesse social na identificação da produção intelectual textual, sua caracterização, seleção e mapeamento para possíveis usos posteriores.

Como dissemos, até o século XIX, muitas bibliografias foram produzidas e as bibliotecas se ampliaram, o que concorreu para 0 aprimoramento de seus métodos de trabalho e para a clareza de seus objetivos e, por sua vez, para a explicitação da relação entre a função das bibliografias e a das bibliotecas. De fato, as técnicas seculares de produção de bibliografias contribuíram para o desenvolvimento dos catálogos das bibliotecas. Além disso, as bibliografias foram adotadas como fontes de informação nas bibliotecas, ou seja, constituíram seu acervo, posteriormente, tornando-se bases de dados online oferecidas 
para consulta em seus espaços. Essa relação é pouco compreendida no ensino e na pesquisa no Brasil, entre outros motivos, porque, se as bibliografias são pouco conhecidas como produto típico de uma época que foi tomando novos contornos no decorrer do tempo, a biblioteca - de maior presença no imaginário social - recebe olhares que oscilam entre a valorização militante e a previsão apocalíptica de desaparecimento. Desse modo, a biblioteca, ora é enunciada como o ambiente que define - por si mesma e de modo exclusivo - as atividades praticadas no campo, ora é negligenciada, neste caso, levando à ausência de referenciais para o ensino, a pesquisa e a prática profissional. A despeito da situação apresentada, o trabalho em bibliotecas é um trabalho bibliográfico que, para além do fazer bibliográfico propriamente dito, agrega as atividades de coleta, ordenação e preservação de documentos, e os produtos, serviços e demais ações a públicos determinados.

Neste sentido, é produtivo elaborar continuamente o objeto subjacente às diversas ênfases construídas em tempos e espaços particulares sob denominações próprias. Seguindo esta linha de raciocínio, é possível constatar a singularidade do conhecimento que se ocupa da produção de referências de documentos selecionados, em ambientes como bibliotecas ou outros sistemas e serviços bibliográficos, colocados à disposição de um público, o qual, a partir destes recursos bibliográficos, é ativado quanto à validade daqueles documentos para as atividades que desenvolve ou poderia desenvolver. Independente do nome, mas considerando a contribuição da Bibliografia, estamos tratando de campo finalístico, ou teleológico, no sentido de que ele depende - para sua existência como tal - de fundamentação científica de cunho teórico, técnico, tecnológico e pragmático.

O trabalho bibliográfico é, portanto, aquele que se ocupa de referenciar o conhecimento produzido por meio de sistemas, serviços e demais ações que possibilitem o uso qualificado da informação.

\section{A apropriação da Bibliografia pela Escola de Ciência da Informação da UFMG}

A origem da Escola de Ciência da Informação da UFMG remonta ao ano de 1950 quando se deu a criação do então chamado Curso de Biblioteconomia de Belo Horizonte, na forma de convênio firmado entre a Secretaria de Educação do Estado de Minas Gerais e o Instituto Nacional do Livro. Já com o nome de Curso de Biblioteconomia de Minas Gerais, foi incorporado, em 1963, à Universidade de Minas Gerais, atualmente UFMG. Em 1976, foi criado o Curso de Pós-Graduação em Biblioteconomia (Administração de Bibliotecas) (KREMER, 2000), um dos primeiros do Brasil neste campo. Posteriormente, dois novos cursos de graduação 
foram implementados na atual Escola de Ciência da Informação, respectivamente em 2009 e 2010: o de Arquivologia e o de Museologia.

\subsection{Organização departamental}

Constituindo-se em torno da produção de conhecimentos, as universidades brasileiras estruturam-se administrativamente segundo as concepções epistemológicas pelas quais optaram, de modo a desenvolver as atividades relativas às áreas de conhecimento de sua especialização. Dito de outro modo, a possibilidade de uma universidade atingir seus objetivos acadêmicos é dependente, em grande medida, desta estruturação. Assim, as universidades têm nas unidades acadêmicas faculdades, escolas, institutos - o primeiro nível de sua divisão administrativa. No entanto, as universidades são, em geral, originadas a partir de cursos, os quais são reunidos em departamentos segundo composições disciplinares específicas, por sua vez, organizados em unidades acadêmicas. Os departamentos gerenciam a contratação dos professores e sua vida institucional, segundo a configuração disciplinar sob a qual são constituídos. Assim, o conhecimento com o qual uma unidade trabalha - e mais do que isso, o modo como esse conhecimento é abordado - pode ser observado a partir da organização departamental adotada.

O Curso de Biblioteconomia foi incorporado à Universidade de Minas Gerais, em 1963, segundo dissemos, como instituição complementar anexa ao Departamento Cultural da Reitoria. No mesmo ano, com a aprovação do Regimento da Escola de Biblioteconomia de Minas Gerais, foi feita uma primeira divisão departamental, com fins didáticos e administrativos, cujo critério foi o agrupamento de disciplinas em: 1) História do Livro e das Bibliotecas, Paleografia; 2) Introdução aos Estudos Históricos e Sociais, Evolução do Pensamento Filosófico e Científico, História da Literatura, História da Arte, Bibliografia Especializada; 3) Bibliografia Geral, Referência, Documentação; e 4) Catalogação, Classificação, Organização e Administração de Bibliotecas, Prática Bibliotecária (KREMER, 2000, p. 18). Desse modo, cada um dos quatro departamentos foi denominado - literalmente - segundo os nomes das principais disciplinas de que eram compostos. A divisão não condizia propriamente com uma configuração disciplinar, pois foi mantida assim na falta de uma síntese que permitisse chegar a denominações representativas dos conteúdos matrizes do curso. De fato, é possível identificar inconsistências. Uma delas pode ser observada no Departamento 2, sob o qual foram reunidas a disciplina Bibliografia Especializada e disciplinas relativas a diversas áreas do conhecimento, enquanto no Departamento 3 estava alocada a disciplina Bibliografia Geral, pertencente ao mesmo campo disciplinar da primeira, além da 
disciplina Documentação que se desenvolveu de modo bastante similar àquela.

Em 1973, foi aprovado o texto do Regimento da Escola de Biblioteconomia da UFMG, no qual dois departamentos foram formalizados: o Departamento de Biblioteconomia e o Departamento de Bibliografia e Documentação (KREMER, 2000, p. 19). A atuação dos Departamentos, segundo a distribuição de disciplinas realizada no início dos anos 1970 (CESARINO, 1973), é a que segue. O Departamento de Biblioteconomia (DB) englobava as disciplinas: Introdução à Biblioteconomia, História do Livro e das Bibliotecas, Seleção de Material Bibliográfico e Audiovisual, Catalogação I e Catalogação II, Catalogação de Materiais Especiais, Classificação I e Classificação II, Técnica do Serviço de Referência, Automação dos Serviços de Bibliotecas, Administração Geral, Organização e Administração I e Organização e Administração II, Metodologia da Pesquisa em Biblioteconomia; e as disciplinas optativas: Bibliotecas de Empresas, Bibliotecas Universitárias, Administração de Bibliotecas, Planejamento de Bibliotecas, Publicações Periódicas em Bibliotecas. Já o Departamento de Bibliografia e Documentação (DBD) contemplava as disciplinas: Evolução do Pensamento Científico, Evolução do Pensamento Filosófico, História da Arte, História da Literatura, Introdução aos Estudos Históricos e Sociais, Bibliografia, Bibliografia Geral, Bibliografia Especializada I e Bibliografia Especializada II, Introdução à Documentação, Documentação I e Documentação II, Reprografia, Arquivística, Paleografia; e as disciplinas optativas: Bibliografia e Referência em Ciências Biológicas, Bibliografia e Referência em Ciências Exatas, Bibliografia e Referência em Ciências Humanas e Sociais, Bibliografia e Referência em Tecnologia, Serviços de Documentação em Bibliotecas Especializadas. Outras disciplinas foram eleitas como interdepartamentais, quais sejam: Estágio Obrigatório, Seminário para Elaboração do Trabalho de Conclusão de Curso, e Estudos dos Problemas Brasileiros I e Estudos dos Problemas Brasileiros II.

Tanto o currículo em curso em 1973 quando os dois novos Departamentos foram formalizados, quanto o currículo implementado no ano seguinte (ASSUNÇÃO; FIUZA, 1974, p. 225-229), eram organizados do seguinte modo quanto aos Departamentos: o Departamento de Biblioteconomia se ocupava do Setor de Catalogação e Classificação e do Setor de Organização e Administração; e o Departamento de Bibliografia e Documentação gerenciava 0 Setor de Bibliografia, o Setor de Documentação e o Setor Cultural.

A esta altura se entendia a Biblioteconomia como o conjunto de atividades de gestão de bibliotecas, incluindo a organização da informação dos acervos constituídos e os serviços aos seus públicos. A Bibliografia relacionava-se ao conjunto das técnicas de produção de bibliografias independente do acervo de uma dada biblioteca, como as bibliografias 
nacionais, as temáticas e as de autor, e o estudo de bibliografias existentes para que fossem oferecidas aos usuários de bibliotecas. Já a Documentação envolvia essencialmente a automação e os processos de recuperação da informação, além da organização e gestão dos centros de documentação e serviços de informação. Podemos dizer que o foco de atuação do Departamento de Biblioteconomia era o de gestão de bibliotecas, no que tange a seus acervos e serviços a públicos locais, enquanto o Departamento de Bibliografia e Documentação tinha como foco de atuação 0 trato com documentos voltados a produtos bibliográficos e serviços de referência, não necessariamente no contexto de bibliotecas, além das disciplinas de formação cultural geral, como eram chamadas. Desse modo, entendemos que, neste período, as denominações de cada Departamento eram orientadoras dos conteúdos com que trabalhavam, e consistentes quando aos objetos e conceitos em jogo.

No entanto, mudanças foram efetivadas na orientação do curso a partir do currículo de 1974, no qual se buscou dar menor ênfase às disciplinas denominadas 'técnicas', por meio da diminuição das disciplinas e da carga horária dos conteúdos de organização da informação (relativos à produção de catálogos e de bibliografias) e da ampliação da carga horária da disciplina Administração e da disciplina Organização e Administração de Bibliotecas (ASSUNÇÃO; FIUZA, 1974, p. 223-226). Mais à frente, ocorreu a determinação do Conselho Federal de Educação para adoção do Currículo Mínimo de Biblioteconomia, aprovado em 1982, que deveria ser feita até o ano de 1985. Para tanto, muitos esforços foram empreendidos e o currículo pleno de Biblioteconomia foi implementado em 1985, seguido por ajustes implementados em 1990.

Foi nesse contexto que uma readequação dos departamentos entrou na pauta da instituição. Em 1983, houve solicitação de remanejamento de professores do Departamento de Biblioteconomia, agora mais centrado em administração e tecnologia, para o Departamento de Bibliografia e Documentação, em que foram alocados os conteúdos de tratamento da informação e de fontes de informação. Para a distribuição de disciplinas entre os Departamentos, foi criada Comissão ad hoc com a função de elaborar uma proposta (UFMG, 06/10/1983). A Comissão buscou definir critérios lógicos no que tange aos teor das disciplinas - pois entendia que algumas disciplinas poderiam compor qualquer um dos departamentos -, associados ao critério de equivalência de carga horária entre os departamentos (a despeito da ponderação de professores quanto à preocupação maior com o aspecto didático que com o formal, o que envolvia a não necessidade de departamentos do mesmo tamanho) (UFMG, 28/03/1984). Neste mesmo ano, a divisão de disciplinas por Departamento, aprovada pelo Conselho Departamental da Escola, indicava relativa coerência disciplinar intradepartamental (à exceção das disciplinas 
optativas), mas não entre o conjunto de disciplinas de cada Departamento e a denominação atribuída a eles (UFMG, 27/10/1983, anexo 1). De fato, a esta altura, já estava evidente uma espécie de inversão entre os Departamentos, principalmente porque o de Biblioteconomia deixou de ser caracterizado pelas disciplinas de organização da informação, as quais foram migradas para o outro Departamento. A divisão de disciplinas foi intencionalmente orientada para uma caracterização do Departamento de Biblioteconomia em torno dos assuntos gestão, tecnologia, usuários e cultura, enquanto o Departamento de Bibliografia e Documentação era voltado aos aspectos introdutórios do campo, tratamento da informação, fontes de informação.

A distribuição de disciplinas após os ajustes curriculares implantados em 1990 (CESARINO; VIANNA, 1990) manteve as inconsistências existentes em princípios da década de 1980. Neste momento, o Departamento de Biblioteconomia (DB) tinha como atribuições, basicamente, as disciplinas: Biblioteca e Sociedade, Cultura e Informação, Formação e Desenvolvimento de Acervo, Preservação do Acervo de Bibliotecas, Estudos de Usuários de Bibliotecas, Introdução à Automação de Serviços de Bibliotecas, Automação de Bibliotecas, Administração de Bibliotecas I, Planejamento de Bibliotecas, Métodos e Técnicas de Pesquisa em Biblioteconomia; além das disciplinas optativas: Materiais Especiais em Bibliotecas, Serviços de Extensão em Bibliotecas, Tecnologia de Informação; e disciplinas que poderiam ser oferecidas como tópicos especiais em: Administração de Bibliotecas, Automação de Serviços de Bibliotecas, Bibliotecas e Ação Cultural. O Departamento de Bibliografia e Documentação (DBD), por sua vez, passou a ser responsável pelas disciplinas: Informação e Biblioteconomia, Produção de Registros do Conhecimento, Tratamento da Informação I e Tratamento da Informação II, Teoria da Classificação e Indexação, Organização e Controle Bibliográfico da Informação, Fontes de Informação Geral, Fontes de Informação Especializada, Disseminação da Informação, Administração de Bibliotecas II, Elaboração e Apresentação do Trabalho Científico; além das disciplinas optativas: Arquivos Administrativos, Arquivos Especializados e Arquivos de Custódia, Paleografia, Processamento Técnico de Coleções Especiais; e disciplinas que poderiam ser oferecidas como tópicos especiais em: Centros de Informação (populares, gerenciais), Preservação de Acervos de Bibliotecas e de Arquivos, Treinamento de Usuário, Classificação Bibliográfica. Estágio Supervisionado $A$ e Estágio Supervisionado B eram disciplinas interdepartamentais e demais disciplinas eram ministradas por outras unidades.

A nova distribuição de disciplinas evidencia, principalmente, a recorrência da palavra biblioteca nos nomes das disciplinas do Departamento de Biblioteconomia, mas também as palavras acervos, usuários e serviços. Já o Departamento de Bibliografia e Documentação 
incorporou disciplinas de tratamento da informação e de fontes de informação, cujos nomes não eram compostos por espaços específicos de trabalho, embora centrados em métodos e instrumentos usualmente disseminados para uso em bibliotecas. A despeito de sua nomenclatura, o Departamento de Bibliografia e Documentação assumiu a disciplina que trata de elementos introdutórios da Biblioteconomia. Este Departamento incluiu, ainda, disciplinas cujos nomes tratam de espaços que não a biblioteca, como centros de informação popular e gerenciais, além de arquivos, embora tenha incorporado, secundariamente, disciplinas que adotem os nomes bibliotecas, acervos e usuários. Podemos observar, também, a presença indiscriminada, nos dois Departamentos, dos mesmos conteúdos disciplinares: a disciplina Administração de Bibliotecas I era de responsabilidade de um Departamento, enquanto Administração de Bibliotecas II era de outro. O mesmo ocorreu com as disciplinas Estágio Supervisionado A e Estágio Supervisionado B.

Muito provavelmente em função deste percurso, o Departamento de Bibliografia e Documentação passou a denominar-se Departamento de Organização e Tratamento da Informação (DOTI), em 1992, e, anos depois, em 2001, o Departamento de Biblioteconomia passou a denominar-se Departamento de Teoria e Gestão da Informação (DTGI) (CALDEIRA, 2010, p. 3), denominações que permanecem até hoje. Quanto a elas, algumas questões se colocam, mas que não serão exploradas aqui, tais como: o significado da duplicidade de termos organização e tratamento - adotados no DOTI, assim como, a não representatividade dos outros conteúdos em sua denominação, e o papel exercido pela teoria nas disciplinas sob responsabilidade do DTGI, que leva esse termo em sua denominação.

Sintetizando, os conteúdos organizados de modo disciplinar nos Departamentos em 1973 foram alterados a partir do currículo de 1974, mas principalmente no decorrer da década de 1980, sem que houvesse alteração denominativa correspondente, o que ocorreu apenas em 1992 e em 2001, por sua vez, na ausência de estudos sobre a especificidade de cada Departamento e a pertinência entre os conteúdos atribuídos e a denominação a ser adotada. Ou seja, a despeito de várias questões internas e externas, não houve rigor suficiente nas decisões tomadas no que tange à relação entre significantes e significados.

A dificuldade de gestão acadêmica, que já vinha ocorrendo, acentuou-se após a implementação dos cursos de Arquivologia e Museologia, entre 2009 e 2010, cujos professores foram contratados indistintamente pelos dois departamentos, seguindo apenas o critério de equidade quantitativa entre professores de um curso ou de outro para alocação departamental.

Cada organização departamental proposta demonstra a concepção epistemológica de seu tempo e lugar, ao mesmo tempo em que indica as 
soluções possíveis frente aos distintos olhares dos professores e aos que circunstancialmente predominaram, por razões diversas, nos movimentos que conduzem às tomadas de decisão.

Os conteúdos sobre a relação entre bibliotecas e bibliografias e o percurso institucional apresentado permitem identificar, nas denominações departamentais 'Biblioteconomia' e 'Bibliografia e Documentação' e nas disciplinas que Ihes corespondiam nas décadas de 1970 até meados da década de 1980, maior consistência e pertinência em termos dos aspectos histórico-conceituais do campo. Por este motivo, supomos que, ao menos quanto a este aspecto, a organização departamental daquele período ofereceu melhores condições de funcionamento administrativo-acadêmico. Quanto às mudanças de orientação da Escola de Biblioteconomia que se refletiram na organização departamental, constatamos que estava colocado o desafio da superação da distinção entre produção de catálogos de bibliotecas e produção de repertórios bibliográficos, juntamente com o avanço da pesquisa no campo que se processava em todo o mundo. Os aspectos teóricos e metodológicos do trabalho bibliográfico mostraram-se norteadores da organização acadêmica necessária ao campo em um determinado momento da Escola, e sua revisitação contínua é movimento necessário, não só ao funcionamento da instituição, mas antes, ao alcance efetivo de seus objetivos acadêmicos.

\subsection{Ensino de graduação}

Como tratado em Ortega (2013) a partir dos artigos publicados sobre o Curso de Biblioteconomia da UFMG, temos o que segue.

O Curso, iniciado em 1950, tinha duração de um ano e era composto por cinco disciplinas: Bibliografia e Referência, Catalogação, Classificação, História da Literatura, História do Livro e das Bibliotecas. Em 1953, o curso passou a ter duração de dois anos, em 1957 passou para três anos, até que, em 1985, o período de duração do curso foi organizado em quatro anos, como é até hoje.

O desenvolvimento progressivo da proposta disciplinar inicial, resultando em alteração da duração do curso de um ano para três, levou a que, até o ano de 1973, houvesse uma ampliação de conteúdos então entendidos como da 'área técnica', com o desdobramento desses conteúdos em várias disciplinas de Catalogação, de Classificação, de Bibliografia e de Documentação. A partir do currículo de 1974, foi feita uma reflexão sobre a experiência dos anos anteriores que conduziu a uma redução da carga horária das disciplinas entendidas como de 'caráter puramente técnico' (como dissemos anteriormente), visando dar ênfase às atividades-fim das bibliotecas e serviços de informação. Esse percurso de desenvolvimento curricular permite observar o pensamento, presente 
ainda hoje no campo, em que se busca privilegiar atividades-fim na ausência da articulação com as atividades-meio que permitiriam elaborar aquelas, estando em jogo o trabalho bibliográfico que, segundo definimos, é peça fundamental da formação no campo. É possível perceber também que a organização departamental proposta na Escola em 1973 encontra equivalência na concepção epistemológica curricular realizada nesta década, sendo, a partir daí, transformada paulatinamente, como tratamos.

Após o currículo de 1985, no de 1998, foram incluídas duas ênfases ao curso: Gestão de Coleções e Gestão da Informação. A primeira era direcionada à gestão de acervos envolvendo coleta de documentos, organização da informação e serviços aos usuários, em instituições como bibliotecas e outros, enquanto a segunda privilegiava atividades voltadas ao acesso e uso de recursos informacionais, em quaisquer formas que se apresentem ou locais em que se encontrem, a depender das demandas, como no caso do profissional autônomo. As ênfases funcionavam a partir de disciplinas optativas que eram atribuídas a cada uma delas e buscavam refletir mudanças já em andamento no curso de pós-graduação, que tratamos à frente. Podemos observar, na explicação sobre as ênfases, relativa equivalência entre conteúdos de Biblioteconomia e a ênfase de Gestão de Coleções e entre conteúdos de Bibliografia e a ênfase de Gestão da Informação, se considerarmos, respectivamente, a divisão do trabalho em gestão de acervos localmente constituídos e na elaboração de produtos a partir de quaisquer outros recursos informacionais. No entanto, segundo a explicação apresentada para as ênfases e suas denominações, inferimos que a noção de coleção que é resultante do processo de seleção foi orientada ao ambiente da biblioteca ou instituições congêneres, mas não aos serviços de informação bibliográfica fora destes ambientes, enquanto a noção de informação foi privilegiada apenas nos casos em que não estivessem em questão acervos localmente constituídos. Supomos que, frente a esta inconsistência sobre termos fundamentais do campo coleção e informação - , as ênfases foram retiradas no processo de revisão curricular que se seguiu. Assim, ainda que possamos observar minimamente a herança da disciplina Bibliografia neste momento do curso, o trabalho bibliográfico em si não foi abordado devidamente.

Por fim, o atual currículo do Curso de Graduação em Biblioteconomia, implantado em 2009, foi produto de revisão orientada à constituição de um conjunto de disciplinas comuns aos currículos - então criados - dos cursos de Arquivologia e de Museologia, que foi chamado de tronco comum. Com o tempo, no entanto, muitas das disciplinas comuns aos três cursos passaram a ser ministradas separadamente. Além disso, o movimento de criação do tronco comum levou a algumas distorções, como a alteração da ordem lógica de disciplinas de organização da informação, assim como, a mudança de disciplinas cujos nomes eram relativos a 
tipologias de instrumentos para disciplinas nomeadas segundo instrumentos específicos. Essas alterações causaram impacto no ensino, demandando questionamentos, tão logo foram implantadas.

O quadro abaixo apresenta as disciplinas que compuseram os currículos do Curso de Graduação em Biblioteconomia da UFMG desde sua criação, relativas aos conteúdos de Bibliografia e de Documentação, uma vez que esta disciplina foi proposta como desenvolvimento daquela, como tratamos anteriormente.

\begin{tabular}{|c|c|}
\hline $\begin{array}{l}\text { PERÍODO E } \\
\text { DURAÇÃO }\end{array}$ & DISCIPLINAS RELATIVAS À BIBLIOGRAFIA E À DOCUMENTAÇÃO \\
\hline $\begin{array}{l}1950-1952 \\
(1 \text { ano })\end{array}$ & - Bibliografia e Referência \\
\hline $\begin{array}{l}1953-1956 \\
(2 \text { anos })\end{array}$ & - Bibliografia e Referência I e II \\
\hline $\begin{array}{l}1957-1961 \\
(3 \text { anos })\end{array}$ & $\begin{array}{l}\text { - Bibliografia e Referência I e II (em 1961, foi acrescida a disciplina Bibliografia e Referência III) } \\
\text { - Documentação }\end{array}$ \\
\hline $\begin{array}{l}1962-1964 \\
(3 \text { anos })\end{array}$ & $\begin{array}{l}\text { - Bibliografia Geral e Referência } \\
\text { - Bibliografia Especializada I e II } \\
\text { - Documentação }\end{array}$ \\
\hline $\begin{array}{l}1964-1968 \\
(3 \text { anos })\end{array}$ & $\begin{array}{l}\text { - Bibliografia Geral e Referência } \\
\text { - Bibliografia Especializada I e II } \\
\text { - Documentação I e II }\end{array}$ \\
\hline $\begin{array}{l}1968-1974 \\
(3 \text { anos })\end{array}$ & $\begin{array}{l}\text { - Bibliografia } \\
\text { - Bibliografia Geral } \\
\text { - Bibliografia Especializada I e II } \\
\text { - Introdução à Documentação } \\
\text { - Documentação I e II } \\
\text { - Disciplinas optativas: disciplinas de Bibliografia e Referência em áreas específicas }\end{array}$ \\
\hline $\begin{array}{l}\text { Currículo de } 1974 \\
(3 \text { anos) }\end{array}$ & $\begin{array}{l}\text { - Bibliografia e Referência } \\
\text { - Bibliografia Especializada } \\
\text { - Bibliografia Brasileira } \\
\text { - Introdução à Biblioteconomia e à Documentação } \\
\text { - Documentação } \\
\text { - Disciplinas optativas: disciplinas de Bibliografia em áreas específicas }\end{array}$ \\
\hline $\begin{array}{l}\text { Currículo de } 1985 \text { e ajustes } \\
\text { implantados em } 1990 \\
\text { (4 anos) }\end{array}$ & $\begin{array}{l}\text { - Tratamento da Informação I (processos de catalogação e referenciação bibliográfica, e estudo de } \\
\text { índices de livros, catálogos de bibliotecas e bibliografias) } \\
\text { - Organização e Controle Bibliográfico da Informação } \\
\text { - Fontes de Informação Geral } \\
\text { - Fontes de Informação Especializada } \\
\text { - Elaboração e Apresentação do Trabalho Científico }\end{array}$ \\
\hline $\begin{array}{l}\text { Currículo de } 1998 \\
(4 \text { anos })\end{array}$ & $\begin{array}{l}\text { - Organização e Controle Bibliográfico da Informação } \\
\text { - Fontes de Informação Geral } \\
\text { - Fontes de Informação Especializada } \\
\text { - Normalização Bibliográfica }\end{array}$ \\
\hline $\begin{array}{l}\text { Currículo de } 2009 \\
(4 \text { anos })\end{array}$ & $\begin{array}{l}\text { - Organização Bibliográfica Nacional } \\
\text { - Introdução às Fontes de Informação } \\
\text { - Fontes de Informação para Pesquisadores e Profissionais } \\
\text { - Acesso a Fontes de Informação em Meio Digital } \\
\text { - Elaboração e Apresentação do Trabalho Científico }\end{array}$ \\
\hline
\end{tabular}

Quadro 1 - Disciplinas relativas aos conteúdos de Bibliografia e de Documentação. Fonte: reformulado de Ortega (2013, p. 193-194).

Como podemos observar no quadro das disciplinas, os conteúdos de Bibliografia foram ganhando espaço e se especializando a partir de 1953 até o currículo de 1974. Neste currículo, foi eliminada a disciplina que incluía os métodos de produção de bibliografias. No currículo de 1985, o 
nome Bibliografia deixou de ser utilizado e seus conteúdos passaram a compor apenas disciplinas que trabalham a descrição de fontes de informação e uma disciplina sobre controle bibliográfico. Esta última disciplina, em 2009, teve seu escopo diminuído passando a denominar-se Organização Bibliográfica Nacional.

Por sua vez, os conteúdos relativos à Documentação podem ser observados do seguinte modo. Uma disciplina com esta denominação foi introduzida no currículo em 1957, com ampliação para o número de três disciplinas no decorrer da década de 1960, ocorrendo a diminuição sobre estes conteúdos no currículo de 1974, que foram completamente eliminados no currículo de 1985. As disciplinas incluíam conteúdos como: Bibliografia; conceito de documento e de informação; tratamento de documentos pela Classificação Decimal Universal (CDU); mecanização e reprografia, depois os processos de automação da recuperação da informação; organização da informação e órgãos internacionais relacionados, como FID, UNESCO e IFLA; normalização de trabalhos acadêmicos e de referências; descrição bibliográfica, indexação e elaboração de resumos, incluindo tesauros; e serviços de documentação em bibliotecas especializadas. Em comparação às disciplinas de Bibliografias, estas se apresentam no tempo de modo menos linear, incluindo diferenças significativas de orientação de um programa para outro, a despeito de indicarem maior coerência e continuidade até a década de 1970.

De fato, a Documentação não foi incorporada à Escola. Observamos sua presença apenas nos primeiros anos do curso de graduação e nos conteúdos correntes de normalização de trabalhos acadêmicos. Considerando a Documentação como continuadora da Bibliografia a partir da ênfase em outros aspectos, podemos dizer que a Escola se centrou na orientação oferecida por esta última, descontinuando mais rapidamente e de modo definitivo seus primeiros ensaios sobre os conteúdos daquela. Recentemente, no entanto, alguns professores tratam da Documentação no contexto dos estudos históricos e epistemológicos da Ciência da Informação, assim como, dos processos de organização da informação, na esteira de movimento realizado no país.

Assim, constatamos que os conteúdos de Bibliografia e os de Documentação apresentavam elementos comuns, como os que abarcam os processos de organização da informação: seleção, descrição, ordenação (arranjo), indexação e elaboração de resumos. Alguns processos, além disso, apresentavam equivalência com os tratados nas disciplinas Catalogação e Classificação, o que demonstra que foi ficando evidente a necessidade de uma concepção mais generalizante voltada às relações entre ambientes (por exemplo, a biblioteca) e produtos (como as bibliografias). Neste sentido, no currículo de 1985, optou-se pelo trabalho conjunto de processos de catalogação e de referenciação bibliográfica e de 
alguns de seus produtos, como catálogos de bibliotecas e bibliografias, em uma mesma disciplina, provavelmente em função de esta relação ser presente no Currículo Mínimo de 1982, no qual a então Escola de Biblioteconomia teve atuação marcante. Essa concepção, no entanto, foi eliminada no currículo seguinte.

Os trabalhos de conclusão de curso realizados na antiga Escola de Biblioteconomia, nome que precedeu o atual, são um capítulo à parte neste relato. Esses trabalhos foram atividade obrigatória entre 1956 e 1974, ano em que foram eliminados do currículo. Não encontramos registros formais sobre esta decisão, mas identificamos alguns relatos segundo os quais, como publicado em Ortega (2013, p. 200), a atividade estaria sobrecarregando a agenda dos professores e o futuro curso de pós-graduação teria por função formar pesquisadores, enquanto a graduação focaria sua atenção na formação de profissionais. Com a eliminação da atividade do currículo, os trabalhos produzidos foram retirados do acervo da Biblioteca da Escola (entregues aos autores ou descartados), o que levou a um projeto de extensão em curso, com apoio da atual equipe da Biblioteca, que busca recuperar os trabalhos e resgatar esta história, além de discutir o objetivo dos trabalhos de conclusão de curso em nível de graduação.

Os trabalhos realizados eram monografias acadêmicas, como é característico desta atividade, mas incorporaram também produtos da prática bibliotecária, como bibliografias (temáticas ou das obras de determinados autores), índices de revistas e demais levantamentos. No currículo de 1974, quando a atividade foi suprimida, decidiu-se também pela eliminação da disciplina de Bibliografia em que se realizava o ensino de compilação de bibliografias.

Neste contexto, várias bibliografias das obras de escritores mineiros foram produzidas pelos alunos (CALDEIRA; FREITAS, 1973) no último ano da graduação, na forma de biobibliografias (ou seja, incluindo as biografias dos autores, além do levantamento exaustivo de suas obras). As biobibliografias, produzidas como aprendizado de ferramenta de trabalho profissional, resultaram, também, em fonte de informação especializada, uma vez que tiveram função reconhecida socialmente. Essas biobibliografias foram reconhecidas pelo circuito literário da cidade de Belo Horizonte na época de sua elaboração (1966-1972), e demandadas como importante elemento de um sistema literário então em fase de consolidação, quando a cidade tinha poucas editoras, livrarias e bibliotecas. Por esses motivos, esses trabalhos de natureza bibliográfica aplicada foram marcantes entre autores/obras locais e um potencial público receptor.

Algumas biobibliografias foram publicadas ou indicadas para publicação e citadas em ensaios de literatura brasileira, enquanto outras passaram a ser procuradas desde os anos 2000 quando os arquivos 
literários começaram a ser valorizados pelas universidades e outras instituições de guarda e de pesquisa. Esses repertórios biobibliográficos funcionaram e funcionam como registro e mapeamento de uma produção intelectual específica de um tempo e lugar. Os produtos desta atividade do Curso estavam interligados, na visão da Escola de Biblioteconomia da UFMG, a um momento histórico da cultura do Estado em que se dava um processo dinâmico de intensa produção literária, mas sem o concurso efetivo de outras instituições difusoras, no qual os bibliotecários (ou aprendizes de) foram chamados a participar, cumprindo o seu papel especial de mediadores culturais da informação.

Deste modo, caberia perguntar se, o ensino na Escola e no Brasil, hoje, em grande medida voltado para a formação de acervos de bibliotecas e a produção de seus catálogos, responde a contento pelas competências necessárias à produção de mapeamentos sobre determinados conhecimentos destinados ao acesso e uso por públicos específicos.

\subsection{Ensino em nível de pós-graduação e produção científica}

O Curso de Pós-Graduação em Biblioteconomia (Administração de Bibliotecas), nível Mestrado, teve início em 1976 (VIEIRA, 1990). Em 1991, o Curso teve seu nome alterado para Curso de Pós-Graduação em Ciência da Informação (PAIM, 2000) em função do entendimento de que o ambiente da biblioteca era limitante para o ensino e a pesquisa no campo. A mudança buscou contemplar um mercado de trabalho mais diversificado, secundarizar os referenciais que envolvem o ambiente da biblioteca em prol do elemento 'informação' e inserir conteúdos de diversas áreas que permitissem a ampliação desejada.

Os conteúdos de Bibliografia foram contemplados de modo específico no início do Curso, como no caso da disciplina Princípios e Prática de Bibliografia (VIEIRA, 1977, p. 143). A exemplo das opções realizadas em nível de graduação no período, esses conteúdos foram abandonados posteriormente. No entanto, neste momento de criação do curso de pós-graduação, a especificidade da Bibliografia estava ainda bastante presente na concepção do campo na Escola, embora apresentada em oposição aos processos de trabalho em bibliotecas, que eram compreendidos de modo estático, uma vez que "o conhecimento aprofundado da bibliografia, especialmente da bibliografia brasileira, representaria a volta às origens da profissão, quando o bibliotecário se preocupava mais com os livros e seu conteúdo e menos com os processos de armazená-los" (VIEIRA; LIMA, 1977, p. 132). Segundo as autoras, a profissionalização do bibliotecário, formado pela ênfase em conhecimentos 
técnicos, teria contribuído para a diminuição de seu status social. Deste modo, buscando tratar de uma política para a pós-graduação no campo, Vieira e Lima (1977, p. 133) propõem a Bibliografia como uma das áreas de concentração para programas neste nível de ensino, a qual foi explicada como: "estudos avançados de recursos bibliográficos, envolvendo técnicas de produção, comercialização e seleção, com ênfase em levantamentos da bibliografia e no estabelecimento de coleçõespadrão para tipos diversos de biblioteca".

Já em uma análise recente sobre o percurso do Programa, se considerarmos que a produção de bibliografias foi contemplada, de algum modo, pela área chamada Organização da Informação, constatamos que apenas pouco mais de $10 \%$ do montante de trabalhos produzidos pelos discentes, de 1978 a 2011, tratou deste tema (ORTEGA, 2013). O primeiro trabalho defendido sobre Organização da Informação é de 1980 e o segundo ocorreu apenas 15 anos depois (1995). A partir daí a produção sobre Organização da Informação é contínua e mais específica quanto ao tema, incluindo, a partir de 2002, muitos trabalhos com enfoque tecnológico. No geral, o sistema de informação foi estudado como produto finalizado, no caso dos estudos de uso de fontes de informação, ou quanto à sua construção, no caso da abordagem tecnológica. A análise permite constatar que os aspectos teóricos e metodológicos de construção e manutenção dos sistemas não foram privilegiados, ou seja, a Organização da Informação foi temática secundária no Programa, o que explica que tenha demorado quase duas décadas para se fazer presente. Desse modo, podemos dizer que a intenção de ampliar o trabalho informacional para além do ambiente de biblioteca no quesito das respostas às demandas por informação não foi concretizada por meio da produção e gestão dos diversos sistemas de informação bibliográfica.

Nos últimos dois anos, no entanto, a Escola de Ciência da Informação passou a ser composta por dois programas de pós-graduação, sendo um deles a reformulação do anterior sob o mesmo nome (Programa de Pós-Graduação em Ciência da Informação (PPGCI) e o outro denominado Programa de Pós-Graduação em Gestão e Organização do Conhecimento (PPG-GOC), de tal modo que será preciso analisar mais à frente o papel atribuído ao trabalho bibliográfico em ambos os Programas.

Quanto à produção de conhecimento sobre Bibliografia pelos professores da Escola, constatamos centralidade dos temas controle bibliográfico e fontes de informação, o que se refletiu na orientação temática da produção discente em nível de pós-graduação, de que tratamos. É preciso ressaltar, como dissemos inicialmente, que essa produção é única em termos nacionais, como podemos observar pela lista de referências dos artigos e livros produzidos, apresentada ao final deste artigo no Anexo 1. A lista de referências demonstra produção intensa sobre o tema da Bibliografia nas décadas de 1970 e 1980, que diminuiu 
nas décadas seguintes, até praticamente não se configurar como tema de pesquisa dos professores. Esta produção de livros e artigos deixa claro, não apenas o volume e diversidade dessa produção grandemente utilizada por professores e alunos de cursos de Biblioteconomia de todo o país, como dá o devido crédito aos professores/pesquisadores da UFMG que contribuíram para o desenvolvimento desse campo teórico no contexto da Biblioteconomia brasileira.

A proposta de ensino em nível de pós-graduação e a orientação da pesquisa que apresentamos, reforçam, junto às diversas estruturas departamentais e o percurso de desenvolvimento do ensino de graduação, a compreensão do campo que se tinha na Escola até a década de 1970, que foi se tornando mais difusa a partir da década seguinte, no que tange ao papel exercido pela Bibliografia, mas também, e principalmente, quanto aos referenciais definidores do campo da Ciência da Informação implicitamente adotados hoje pela Escola.

\section{Considerações finais}

O arco de ascensão e queda da importância dos estudos bibliográficos demonstrado na experiência da Escola de Biblioteconomia da UFMG (posteriormente Escola de Ciência da Informação) com a disciplina Bibliografia num dado período do século passado não foi um caso isolado, mas, ao contrário, espelha uma tendência mundial como apontado por Hazen (2000). O mesmo movimento é lembrado por Serrai e Sabba (2005, p.17) que avaliam como equívoco conceitual a ausência de distinção entre a Bibliografia enquanto ciência, com seus objetos, conteúdos disciplinares e funções, e os repertórios bibliográficos em si mesmos.

Assim, é pertinente afirmar que o progressivo abandono da perspectiva bibliográfica no ensino e na pesquisa contribuiu para, ora ressaltar o estudo e trabalho no ambiente da biblioteca sem explorar sua complexidade, ora para abandonar parcial ou totalmente o conceito de biblioteca sem referências que o substituíssem. Ocorreu o solapamento da ideia de produção bibliográfica como mapeamento do conhecimento registrado passível de ser acessado e utilizado por um público, em prol de certas abordagens, como a prescritiva e normativa - aplicada à catalogação e à elaboração de referências bibliográficas, na perspectiva da adoção de instrumentos predeterminados -, a descritiva - em que se dá a apresentação de fontes de informação predefinidas -, e a tecnológica que, a despeito de seu lugar intrínseco no campo, foi simplesmente acoplada às anteriores.

Deste modo, no ensino, hoje, no Brasil, assim como, na Escola de Ciência da Informação da UFMG, a Bibliografia é passível de ser 
identificada, de modo mais evidente, na produção de referências bibliográficas de trabalhos acadêmicos, para o que a atividade de normalização é sua principal orientação. Assim, passou-se a considerar essencialmente o conjunto das normas para produção de referências citadas em um trabalho. De fato, na Escola em análise, a normalização foi presente nas disciplinas de Bibliografia que tratavam da produção de repertórios bibliográficos, depois nas disciplinas de Documentação, sendo hoje ensinadas, como em outros cursos, na ausência de menção a estas disciplinas.

Considerando a Bibliografia como disciplina cujos produtos decorrem de atividades de avaliação e seleção, e de produção de representações e índices, estes não são meras ferramentas, mas mecanismos sociotécnicos com função reconhecida de acesso orientado à produção de conhecimento. Deste modo, referências bibliográficas são representações documentárias, ou seja, estruturas textuais representativas de documentos e, portanto, indicativas destes e elaboradas para funcionar como instrumentos de comunicação e de acesso do conhecimento produzido.

No ensino, hoje, a produção bibliográfica é representada também pela produção de catálogos de biblioteca, em geral centrados em acervos locais e baseados no modelo predominante anglo-americano de orientação normativa, portanto, sem que se recorra às generalizações que seriam necessárias.

O outro aspecto ainda sobre a Bibliografia no ensino de graduação no Brasil hoje, e fortemente presente na Escola de Ciência da Informação da UFMG, são as fontes de informação. No entanto, a abordagem tende a ser formal e descritiva, além de restritiva, uma vez que os objetos com os quais o profissional trabalha são todos os existentes, ou que existiram um dia, e não apenas aqueles criados com o objetivo de funcionarem como documentos. Faltaria, de partida, definir fontes de informação de forma mais aprofundada.

A configuração epistemológica de um campo é necessária à transposição didática efetivada nos diversos níveis de ensino. Conhecer o campo em que se trabalha contribui para evitar reduções históricas na pesquisa e no ensino, as quais inevitavelmente comprometem as respostas às demandas sociais colocadas a profissionais bibliotecários, assim como, não contribuem para a existência mesma destas demandas.

A referência às disciplinas Bibliografia, Biblioteconomia e Documentação demonstra a complexidade do percurso de construção do campo, complexidade essa que se encontra amplificada em função de confrontamentos insuficientemente realizados ou mesmo de sua ausência. A fragmentação disciplinar da abordagem bibliográfica foi depois acoplada a muitas outras abordagens não bibliográficas, desde as arquivísticas e museológicas, com as quais apresenta relações histórico-conceituais, até 
estudos diversos de relação mais distante. Na perspectiva de parâmetros propriamente científicos, podemos dizer que inexiste - especialmente no Brasil - elaboração coletiva e registrada pertinente e suficiente à singularidade e integralidade do campo. No entanto, é possível identificar construção histórica sobre lugar teórico único, cujo acúmulo de conhecimento deflagra a existência de condições cognitivas necessárias a proposições e confrontamentos.

A questão de fundo desse trabalho é a de construção do pensamento de um campo, e sua apropriação por uma Escola em particular, que, por não ser observado em suas diversas facetas, tem fragilizado sua consolidação científica e seu reconhecimento social. Faz-se necessário, assim, explorar ideias e métodos já propostos no campo, buscando explicitar as ênfases desenvolvidas em cada tempo e lugar, como modo de contribuir para a sistematização de avanços e para a recuperação e atualização do seu eixo identitário. Não se trata de mero resgate do passado, mas da compreensão de que esse movimento é necessário à contemporaneidade, pois o não aprofundamento históricoconceitual compromete o futuro que se constrói a cada dia. É preciso inovar, dizem, mas a grande inovação no campo, hoje, faz-se pelo retorno às suas referências definitórias.

Como a historicidade do campo tem se mostrado uma necessidade cada vez maior em todo o mundo, caberia voltar o olhar para outro campo, registrado no documentário 'Hestórias da Psicanálise: leitores de Freud', de Francisco Capoulade, de 2016. Nele, a frase do psicanalista, psicólogo, escritor e professor Christian Dunker, sobre a apropriação brasileira da Psicanálise, é emblemática dos problemas que enfrentamos devido ao esquecimento contínuo de nossa história. Segundo Christian Dunker: "O que há de mais novo em Psicanálise é Freud mesmo".

Sendo assim, hoje é necessário voltarmos ao óbvio do campo, por meio dos estudos e do ensino do sistema bibliográfico na perspectiva de dispositivo elaborado para funcionar como proposta de percurso cognitivo sobre documentos, com o fim de contribuir para fomentar o uso qualificado da informação, promovendo a inserção cultural do sujeito no mundo informacional científico, artístico, profissional, da cidadania.

\section{Referências}

ASSUNÇÃO, Jandira Batista de; FIUZA, Marysia Malheiros. Reformulação do currículo do Curso da escola de Biblioteconomia da UFMG. Revista da Escola de Biblioteconomia da UFMG, Belo Horizonte, v. 3, n. 2, p. 218233, 1974. 
BALSAMO, Luigi. La bibliografía: historia de una tradición. Gijón: Trea, 1998. (Biblioteconomía y Administración, 20). Publicado originalmente em italiano em 1984.

CALDEIRA, Paulo da Terra. Editorial. Perspectivas em Ciência da Informação, v. 15, n. especial, p. 1-5, nov. 2010.

CALDEIRA, Paulo da Terra; FREITAS, Sônia Maria Penido de. Trabalho de conclusão de curso. Revista da Escola de Biblioteconomia da UFMG, Belo Horizonte, v. 2, n. 1, p. 86-138, 1973.

CAPOULADE, Francisco. Hestórias da psicanálise: leitores de Freud. 2016. Documentário. 96 min.

CESARINO, Maria. Augusta da Nóbrega. O ensino de Biblioteconomia: um currículo a ser mudado. Revista da Escola de Biblioteconomia da UFMG, Belo Horizonte, v. 2, n. 1, p. 43-59, 1973.

CESARINO, Maria. Augusta da Nóbrega; VIANNA, Márcia Milton. O Curso de Graduação em Biblioteconomia da UFMG. Revista da Escola de Biblioteconomia da UFMG, Belo Horizonte, v. 19, n. especial, p. 37-67, 1990.

COUZINET, Viviane. Des pratiques érudites à la recherche: Bibliographie, Bibliologie. In: GARDIÈS, Céciles (Dir.). Approche de l'informationdocumentation: concepts fondateurs. Toulouse: Cépaduès, 2011. p. 167186.

HAZEN, Dan. Bibliographers in the electronic age. Library Trends, v. 48, n. 4, p. 821-841, 2000.

KREMER, Jeannette Marguerite. Cronologia da Escola de Biblioteconomia da UFMG: 1950-2000. Perspectivas em Ciência da Informação, Belo Horizonte, v. 5, n. especial, p. 17-23, jan./jun. 2000.

MENESES TELLO, Felipe. Dimensiones cognitivas de la bibliografía. Revista Interamericana de Bibliotecología, Medellín, v. 30, n. 1, p. 107-134, ene./jun. 2007.

ORTEGA, Cristina Dotta. Contexto de desenvolvimento da Organização da Informação, com enfoque para a Catalogação, na Escola de Ciência da Informação da UFMG. Perspectivas em Ciência da Informação, v. 18, n. 2, p. 182-215, abr./jun. 2013.

PAIM, Ísis. A ciência da informação na UFMG: a trajetória do programa de pós- graduação. Perspectivas em Ciência da Informação, Belo Horizonte, v. 5, n. especial, p. 105-110, 2000.

SERRAI, Alfredo; SABBA, Fiammetta. Profilo di Storia della Bibliografia. Milano: Edizione Sylvestre Bonnard, 2005. 
UNIVERSIDADE FEDERAL DE MINAS GERAIS - UFMG. Escola de Biblioteconomia. Atas de reuniões do Colegiado de Coordenação Didática. Belo Horizonte, 1983-1984.

VIEIRA, Anna da Soledade. A formação de Administradores de Bibliotecas: na berlinda o Programa da UFMG. Revista da Escola de Biblioteconomia da UFMG, Belo Horizonte, v. 6, n. 2, p. 136-160, set. 1977.

VIEIRA, Anna da Soledade. A Pós-Graduação na EB/UFMG: memória e perspectivas. Revista da Escola de Biblioteconomia da UFMG, Belo Horizonte, v. 19, n. especial, p. 68-79, 1990.

VIEIRA, Anna da Soledade; LIMA, Etelvina. A pós-graduação em Biblioteconomia formação de uma liderança nacional. Revista da Escola de Biblioteconomia da UFMG, Belo Horizonte, v. 6, n. 2, p. 125-135, set. 1977.

\section{ANEXO 1 - Produção acadêmica sobre Bibliografia na Escola de Ciência da Informação (em ordenação cronológica)}

\section{Produção de Paulo da Terra Caldeira:}

CALDEIRA, P. T.; FREITAS, Sônia M. P. Trabalhos de conclusão de curso. Revista da Escola de Biblioteconomia da UFMG, v. 2, p. 86-138, 1973.

CALDEIRA, P. T. Guias de referência. Revista da Escola de Biblioteconomia da UFMG, v. 4, p. 242-263, 1975.

CALDEIRA, P. T. Dispersão e produtividade da literatura brasileira de Doença de Chagas. Revista de Biblioteconomia de Brasília, v. 3, p. 113$122,1975$.

CALDEIRA, P. T. Processo de crescimento epidemiológico aplicado à literatura brasileira de Doença de Chagas. Ciência da Informação, v. 4, p. 5-16, 1975.

CALDEIRA, P. T. Periódicos de ciências biomédicas. Revista da Escola de Biblioteconomia da UFMG, v. 5, p. 205-224, 1976.

OLIVEIRA, M. P.; CALDEIRA, P. T. Análise bibliométrica da literatura médica brasileira. Revista da Escola de Biblioteconomia da UFMG, v. 5, p. 7-26, 1976.

CAMPELLO, B. S.; CALDEIRA, P. T. Controle de teses no Brasil. Revista da Escola de Biblioteconomia da UFMG, v. 6, n. 2, p. 196-204, 1977. 
CALDEIRA, P. T. Guia das bibliotecas do Estado de Minas Gerais. Belo Horizonte: Conselho de Extensão da UFMG, 1977. 113 p.

CALDEIRA, P. T. Bibliografia mineira. Revista da Escola de Biblioteconomia da UFMG, v. 7, p. 263-267, 1978.

CARVALHO, M de L. B. de; CALDEIRA, P. T. Algumas organizações ligadas ao controle bibliográfico no Brasil. Revista da Escola de Biblioteconomia da UFMG, v. 7, p. 105-131, 1978.

CALDEIRA, P. T.; CARVALHO, M de L. B. de. Bibliografia retrospectiva: um instrumento para análise do desenvolvimento científico e cultural do Brasil. Revista da Escola de Biblioteconomia da UFMG, v. 9, p. 50-60, 1980.

CALDEIRA, P. T.; CARVALHO, M de L. B. de. O problema editorial da bibliografia brasileira corrente. Revista Brasileira de Biblioteconomia e Documentação, v. 13, p. 210-216, 1980.

CALDEIRA, P. T. O controle bibliográfico na área de biblioteconomia no Brasil. Revista de Biblioteconomia de Brasília, v. 9, p. 77-88, 1981.

CALDEIRA, P. T.; CARVAlHO, M de L. B. de. Fontes para o estudo da Brasiliana. Revista Brasileira de Biblioteconomia e Documentação, v. 15, p. 25-33, 1982.

CALDEIRA, P. T. Bibliógrafos brasileiros: levantamento preliminar. Revista Brasileira de Biblioteconomia e Documentação, v. 16, p. 37-44, 1983.

CALDEIRA, P. T.; CARVALHO, M. de L. B. de. A importância dos recursos bibliográficos brasileiros para os usuários da informação científica. Cadernos de Biblioteconomia, Recife, v. 6, n. 1, p. 137-144, 1983.

CALDEIRA, P. T. Subsídios para a determinação de bibliógrafos brasileiros. Revista da Escola de Biblioteconomia da UFMG, v. 12, p. 88-96, 1983.

CALDEIRA, P. T. A situação do Brasil em relação ao controle bibliográfico universal. Revista da Escola de Biblioteconomia da UFMG, v. 13, p. 260283, 1984.

CALDEIRA, P. T. Duas experiências de ensino da disciplina Bibliografia Brasileira. Revista da Escola de Biblioteconomia da UFMG, v. 14, p. 90105, 1985.

CAMPOS, C. M.; CALDEIRA, P. T. Bibliografia especializada corrente no Brasil: três décadas de descontinuidade. Revista da Escola de Biblioteconomia da UFMG, v. 17, p. 186-213, 1988.

CALDEIRA, P. T. O uso de fontes de informação em uma comunidade ligada a arte: o caso da Escola de Belas Artes da UFMG. Revista da Escola de Biblioteconomia da UFMG, v. 21, p. 34-59, 1988. 
TARGINO, M. das G.; CALDEIRA, P. T. Análise da produção científica em uma instituição de ensino superior: o caso da Universidade Federal do Piauí. Ciência da Informação, v. 17, p. 15-25, 1988.

CAMPELLO, B. S.; CALDEIRA, P. T. Recursos informacionais para o ensino fundamental. Belo Horizonte: Escola de Biblioteconomia da UFMG, 1997. $127 \mathrm{p}$.

CAMPELLO, B. S; CALDEIRA, P. T.; SILVA, A. I. B. da; MANGUE, M. V. Recursos informacionais para 0 ensino fundamental. Ciência da Informação, Brasília, v. 27, n. 3, p. 268-275, 1998.

CAMPELLO, B. S.; CALDEIRA, P. T.; MACEDO, V. A. A. (Orgs.). Formas e expressões do conhecimento: introdução às fontes de Informação. Belo Horizonte: Escola de Biblioteconomia da UFMG, 1998. 414 p.

CALDEIRA, P. T. Museus. In: CAMPELLO, B. S.; CALDEIRA, P. T.; MACEDO, V. A. A. (Orgs.). Formas e expressões do conhecimento: introdução às fontes de Informação. Belo Horizonte: Escola de Biblioteconomia, 1998. 414 p. p. 391-414.

CALDEIRA, P. T. Guias de Literatura. In: CAMPELLO, B. S.; CENDÓN, B. V.; KREMER, J. M. (Orgs.). Fontes de Informação para pesquisadores e profissionais. Belo Horizonte: Editora UFMG, 2000. 319 p. p. 263-274.

CAMPELLO, Bernadete; CALDEIRA, P. T. (Orgs.). Introdução às fontes de informação. Belo Horizonte: Autêntica, 2005. 181 p.

CALDEIRA, P. T. Museus. In: CAMPELLO, B. S.; CALDEIRA, P. T. (Orgs.). Introdução às fontes de informação. Belo Horioznte: Autêntica, 2005. p. 141-157.

CALDEIRA, P. T. Coleção Rita Adelaide. In: CESARINO, M. A. da N. (Org.). Biblioteca Pública Estadual Luiz de Bessa: 50 anos de cultura. Belo Horizonte: Secretaria de Estado de Cultura de Minas Gerais, 2006. p. 8699.

\section{Produção de Bernadete Campello:}

CAMPELLO, B. S. Materiais não convencionais em bibliotecas especializadas. Revista da Escola de Biblioteconomia da UFMG, Belo Horizonte, v. 15, n.1, p. 7-36, 1985.

CAMPELLO, B. S.; ANDRADE, M. E. N. A. Fontes de informação para bibliotecas públicas e comunitárias brasileiras: proposta para seu estudo nos cursos de biblioteconomia. Revista da Escola de Biblioteconomia da UFMG, v. 17, n. 2, p. 173-185, 1988.

CAMPELLO, B. S.; ANDRADE, M. E. A.; MEDEIROS, N. L. A utilização de enciclopédias em bibliotecas públicas e escolares na região metropolitana 
de Belo Horizonte relato de pesquisa. Ciência da Informação, Brasília, v. 22, n. 3, p. 259-262, 1993.

CAMPELLO, B. S.; ANDRADE, M. E. A.; MEDEIROS, N. L.Encicoplédias publicadas no Brasil: um estudo comparativo entre Barsa, Mirador e Delta UNiversal. Ciência da Informação, Brasília, v. 22, n. 1, p. 44-52, 1993.

CAMPELLO, B. S.; BORGES, M. E. N. A organização da informação para negócios no Brasil. Perspectivas em Ciência da Informação, Belo Horizonte, v. 2, n. 2, p. 149-161, 1997.

CAMPELLO, B. S.; MAGALHÃES, M. H. A. Introdução ao controle bibliográfico. Brasília: Briquet de Lemos, 1997. 113 p.

CAMPELLO, B. S.; MONTALLI, K. M. L. Fontes de informação sobre companhias e produtos industriais: uma revisão de literatura. Ciência da Informação, Brasília, v. 26, n. 3, p. 321-326, 1997.

CAMPELLO, B. S.; CALDEIRA, P. T. Recursos informacionais para o ensino fundamental. Belo Horizonte: Escola de Biblioteconomia da UFMG, 1997. $127 \mathrm{p}$.

CAMPELlO, B. S; CALDEIRA, P. T.; SilVA, A. I. B. da; MANGUE, M. V. Recursos informacionais para 0 ensino fundamental. Ciência da Informação, Brasília, v. 27, n. 3, p. 268-275, 1998.

CAMPELLO, B. S.; CALDEIRA, P. T.; MACEDO, V. A. A. (Orgs.). Formas e expressões do conhecimento: introdução às fontes de Informação. Belo Horizonte: Escola de Biblioteconomia da UFMG, 1998. 414 p.

CAMPELLO, B. S.; CAMPOS, C. M. Fontes de Informação especializada: características e utilização. 2. ed. Belo Horizonte: Ed. UFMG, 1998. 160 p.

CAMPELLO, B. S.. Fontes de informação utilitária para bibliotecas públicas. Revista de Biblioteconomia de Brasília, Brasília, v. 22, n.1, p. 35-46, 1998.

CAMPELLO, B. S.; CENDÓN, B. V.; KREMER, J. M. (Orgs.). Fontes de informação para pesquisadores e profissionais. Belo Horizonte: Ed. UFMG, 2000. 319 p.

CAMPELLO, B. S. Encontros científicos. In: CAMPELLO, B. S.; CENDÓN, B. V.; KREMER, J. M. (Orgs.). Fontes de informação para pesquisadores e profissionais. Belo Horizonte: Ed. UFMG, 2000. 319 p. p. 55-71.

CAMPELLO, B. S. Organizações como fonte de informação. In: CAMPELLO, B. S.; CENDÓN, B. V.; KREMER, J. M. (Orgs.). Fontes de informação para pesquisadores e profissionais. Belo Horizonte: Ed. UFMG, 2000. 319 p.

CAMPELLO, B. S. Pesquisas em andamento. In: CAMPELLO, B. S.; CENDÓN, B. V.; KREMER, J. M. (Orgs.). Fontes de informação para 
pesquisadores e profissionais. Belo Horizonte: Ed. UFMG, 2000. 319 p. p. 49-54.

CAMPELLO, B. S. Relatórios técnicos. In: CAMPELLO, B. S.; CENDÓN, B. V.; KREMER, J. M. (Orgs.). Fontes de informação para pesquisadores e profissionais. Belo Horizonte: Ed. UFMG, 2000. 319 p. p. 105-110.

CAMPELLO, B. S. Teses e dissertações. In: CAMPELLO, B. S.; CENDÓN, B. V.; KREMER, J. M. (Orgs.). Fontes de informação para pesquisadores e profissionais. Belo Horizonte: Ed. UFMG, 2000. 319 p. p. 121-128.

CAMPELLO, B. S. Traduções. In: CAMPELLO, B. S.; CENDÓN, B. V.; KREMER, J. M. (Orgs.). Fontes de informação para pesquisadores e profissionais. Belo Horizonte: Ed. UFMG, 2000. 319 p. p. 129-135.

DIAS, E. W.; CAMPELLO, B. S. Literatura comercial. In: CAMPELLO, B. S.; CENDÓN, B. V.; KREMER, J. M. (Orgs.). Fontes de informação para pesquisadores e profissionais. Belo Horizonte: Ed. UFMG, 2000. 319 p. p. 183-190.

CAMPELLO, Bernadete; CALDEIRA, P. T. (Orgs.). Introdução às fontes de informação. Belo Horizonte: Autêntica, 2005. 181 p.

CAMPELLO, B. S. Introdução ao controle bibliográfico. 2. ed. Brasília: Briquet de Lemos Livros, 2006. 94 p.

CAMPELLO, B. S. Museologia: guia de pesquisa. Belo Horizonte: Escola de Ciência da Informação da UFMG, 2012. 49 p. 